\title{
Customer Churns Prediction Model Based on Machine Learning Techniques: A Systematic Review
}

\author{
Venkata Pullareddy Malikireddy ${ }^{1,{ }^{*}}$ Madhavi Kasa ${ }^{2}$ \\ 1,2 Jawaharlal Nehru Technological University Anantapuramu, Anantapur, Andhra Pradesh, India \\ *Corresponding author. Email: mvpullareddy@gmail.coms
}

\begin{abstract}
The customer churn prediction model is required by many companies to predict the risk of customer churn and take necessary actions to prevent churn. Recently, machine-learning techniques are highly applied in customer churn prediction. In this paper, machine learning-based models are applied to the customer churn prediction, which is reviewed with their advantages and limitations. Random Forest methods were highly used in the existing customer churn prediction models due to their advantages of effectively analyzing the features in the data. Feature selection methods such as Particle Swarm Optimization (PSO) and Firefly algorithms were applied to improve the prediction process. The Ensemble classifiers of bagging and boosting of random forest are applied to the prediction of customer churns which achieves higher performance. Deep learning models such as Long Short Term Memory (LSTM) and Convolution Neural Network (CNN) were applied for prediction and achieves higher performance. Random forest model, LSTM, and CNN models have the limitations of overfitting problem of customer churn prediction. Feature selection techniques of PSO and firefly methods have the limitations of poor convergence and lower efficiency in handling the imbalanced dataset.
\end{abstract}

Keywords: Customer Churn Prediction, Firefly Algorithms, Machine Learning Techniques, Particle Swarm Optimization (PSO), Random Forest.

\section{INTRODUCTION}

Customer churn is one of the major concerns for large companies due to its direct effect on the company's revenue, especially in the telecom field. Companies are seeking to develop the customer churn prediction model to predict the risk of customer churns. The telecommunication sector is one of the important fields in the developed countries like India, South Korea, etc. By increasing the number of operators and technical progress the level of competition increases [1]. Customer churns critically affect the business, especially in the telecommunication sector and this sector focuses on retaining the existing customers, which acquires more than the new customers due to the associated high cost [2]. Customer Relationship Management (CRM) is a comprehensive strategy applied for organizing, developing, and strengthening loyalty with long-lasting customer relations which is applied in the telecommunication sector. CRM based on the historical data shows that the cost of a new customer is five to six times more than retaining the existing customer [3]. The advancement of machine learning and artificial intelligence tends to increases the possibilities to predict customer churns with high performance. The Support system and consumer service dissatisfaction is the main reason to the customer churn. Forecasting the customer churning risk helps the companies to deal with the customer churn problem $[4,5]$.

Generally, machine learning techniques analyze the customer characteristics by using the datasets like call details, account and billing information, the future behavior of customers with personal demographics. Initially, data mining techniques are primarily applied to the churn prediction which is predicted by the telecom churners. For instance, neural networks and decision trees are applied to develop accurate churn prediction systems [6, 7]. Various machine learning algorithm was applied to analyze the churning task like artificial neural networks, random forest, the statistical classifier (KNN), logistic regression, decision tree, support vector machines, and Naïve Bayes. The hybrid classification of more than one method was applied in the churn prediction which outperforms the single algorithm $[8,9]$. Various feature selection and classifier methods are applied in the existing customer churn prediction model [10]. In this paper, machine-learning techniques applied 
for the prediction of customer churns were reviewed. Existing models in the customer churn prediction are analyzed with their advantages and limitations. The problem definitions of the existing researches in customer churn prediction were discussed in this study.

This paper is organized as follows: The model overview, feature selection models, ensemble models, machine learning techniques, deep learning models in customer churns prediction were reviewed in section 2 . Comparative analysis of the recent notable techniques in customer churns prediction is given in Section 3. The problem definition of the existing models was given in section 4 and the conclusion of this research paper is given in section 5 .

\section{CUSTOMER CHURNS PREDICTION MODEL OVERVIEW}

Customer churns are one of the major concerns for large companies and especially in the telecommunication field. Customer churns prediction models have been developed to predict the risk of customer churns to take necessary care of the customer. Traditionally, the statistical methods were applied to predict the customer churns and the statistical models which has the limitations of the lower efficiency in the prediction. Machine learning techniques were applied to predict the customer churns which achieves considerable performance in the prediction. Various techniques of machine learning techniques like Random forest, decision tree, and Naïve Bayes were applied for the prediction. Some of the researches involved in applying the feature selection method and parameter estimation method to improve the performance. Ensemble classification methods were applied in the Random forest method to improve the efficiency. Deep learning techniques were applied to the prediction that effectively improves the performance of the method. The overview of the customer churn prediction model is shown in Figure 1.

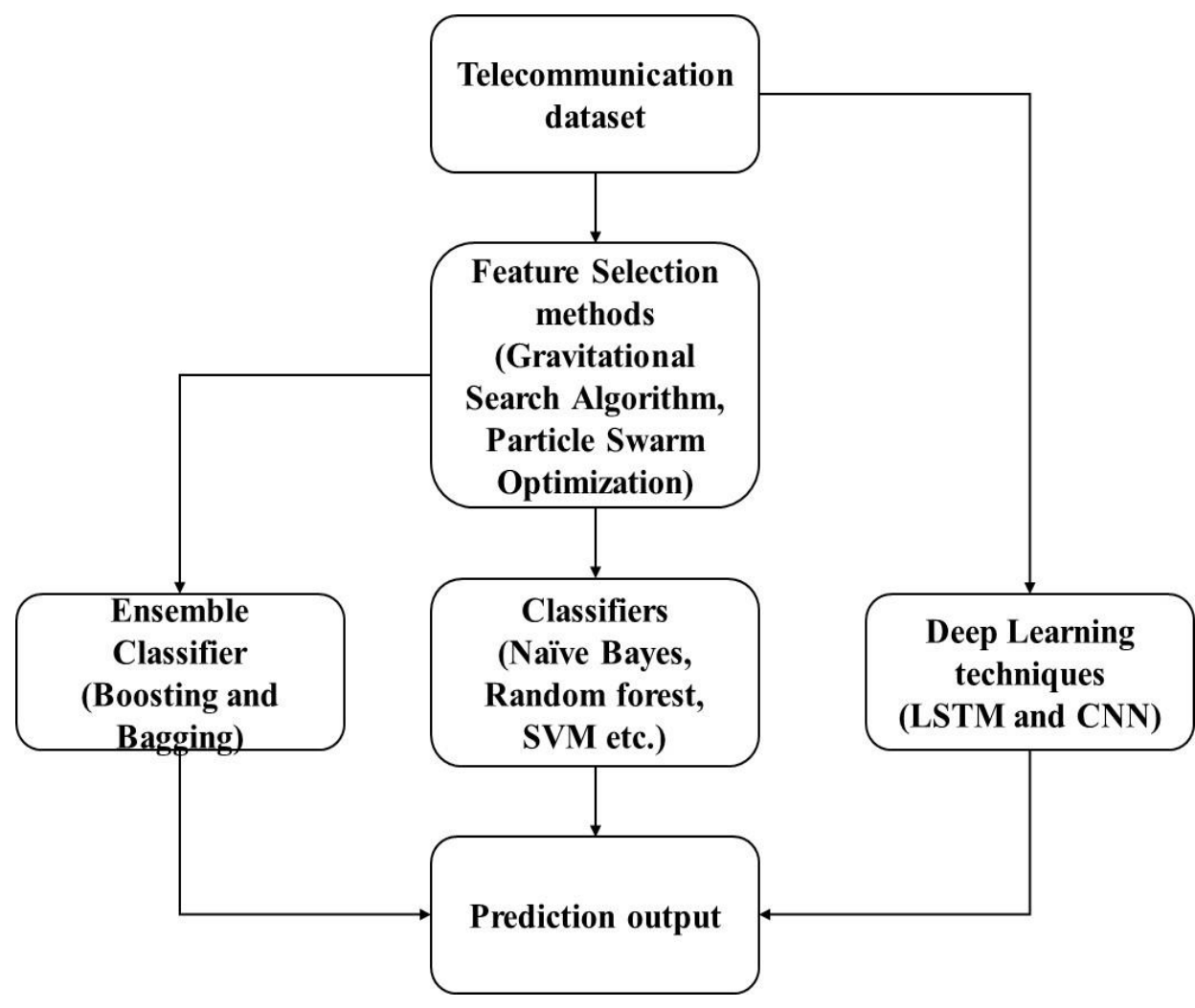

Figure 1 Overview of the Customer Churns prediction model

\subsection{Feature Selection Models}

Feature selection models were applied to select the relevant features from the customer churns datasets. Irrelevant feature selection involves in degrade the performance of the classifiers in prediction.

Amin et al. [2] (2017) applied feature selection methods like LEM2 algorithm (LA), Covering Algorithm
(CA), Genetic Algorithm (GA), and Exhaustive Algorithm (EA) for the prediction. The selected features are applied to the rough set of theories to predict customer churns. The feature selection methods have a lower convergence that affects the performance of the prediction.

Idris et al. [6] (2017) applied Particle Swarm Optimization (PSO) for under-sampling to handle the 
imbalanced dataset. The genetic programming is applied for the feature selection whereas the selected features are applied for the Adaboost classifier. The PSO method has poor convergence effects that perform the prediction model. Óskarsdóttir et al. [11] (2020) applied relational learner as the feature selection for the prediction of customer churns. Social Network data was applied to predict customer churns. This method has a lower performance in the social network data analysis.

Ahmed et al. [12] (2017) applied the firefly algorithm as the classification in the prediction of customer churns. The Firefly algorithm is applied for the feature selection and classification in the Orange dataset. Firefly algorithm has the limitations of poor convergence and high computational time. Ullah, et al. [13] (2019) applied to gain the Information and attribute the feature ranking method to predict the customer churns. Faris [14] (2018) and Vijaya, et al. [15] (2017) applied the PSO method as the feature selection technique.

\subsection{Ensemble Methods}

Some of the researches involved in applying the ensemble classification methods [16-19] for the prediction of customer churns are given below:

Lalwani et al. [4] (2021) applied a gravitational search algorithm to select the features from the customer churns datasets. The selected features were applied in the ensemble classifiers like random forest, support vector machine for the prediction of customer churns. The gravitational search algorithm has the limitations of slow convergence and easily falls into local optima.

Vijaya and Sivasankar et al. [8] (2018) applied the rough set theory of feature selection, and selected features were applied in the ensemble classifiers like Random subspace, bagging and boosting. The ensemble model has the limitation of the lower efficiency in the prediction.

\subsection{Machine Learning techniques}

Machine learning techniques were highly applied in the customer churn prediction that achieved the higher performance of classification. Some of the researches involved in applying the feature selection method and machine learning techniques for efficient classification [20-22].

Mashraie et al. [5] (2020) applied a push-pullmooring framework for the feature selection process and applied it in the classifiers such as random forest, support vector machine, logistics regression for the prediction process. The random forest method has the limitation of overfitting problem when the number of trees in the model is less. The support vector machine method has the limitation of lower efficiency to handle the large dataset.

Faris [14] (2018) applied the PSO method for the feature selection and Feed Forward Neural Network for the prediction of customer churns. The oversampling method is applied to handle the imbalance dataset where the feed-forward neural network has the overfitting problem in the training process. Random forest $[4,5,7$, $8,13]$ has been highly used in the existing customer churns prediction due to its capacity to analyze the relations of features in the dataset. The random Forest method can handle the large dataset.

Support Vector Machine [4, 5] has been applied in the existing customer churn prediction in which the model has the advantage of effectively analyzing the neighbor data instances. Support Vector Machine can handle the large features dataset and has the lower performance in the imbalance dataset.

\subsection{Deep Learning Models}

Deep Learning models [23] were applied in many fields like medical image analysis [24], pattern analysis [25], social media sentiment analysis [26] to achieve high performance. Few existing researchers applied the deep learning methods in the prediction of customer churns [27-29].

Alboukaey, et al. [10] (2020) applied Long Short Term Memory (LSTM) and Convolution Neural Network (CNN) models were applied to the feature selection and classification. The LSTM based models have significantly higher performance compared to the CNN-based models in the prediction. The LSTM and CNN-based models have the limitations of overfitting problems in the training process.

\section{COMPARATIVE ANALYSIS}

Customer churn is one of the important concerns for large companies that directly affects the revenue of the companies, especially it affects the telecom field. Existing researchers apply various machine learning methods to predict customer churn. Some of the notable researches on machine learning techniques to predict the customer churn are compared in this section with advantages and limitations, as shown in Table 1.

Table 1. Existing Researches on machine learning technique to predict the customer churn

\begin{tabular}{|l|l|l|l|}
\hline Author(s) & \multicolumn{1}{|c|}{ Methodology } & \multicolumn{1}{c|}{ Advantages } & \multicolumn{2}{c|}{ Limitations } \\
\hline $\begin{array}{l}\text { Ahmad } \\
\text { et al. }[1] \\
(2019)\end{array}$ & $\begin{array}{l}\text { The XGBOOST algorithm model is applied to } \\
\text { the Random forest method for feature analysis } \\
\text { to the customer churn prediction. }\end{array}$ & $\begin{array}{l}\text { This model applies the } \\
\text { social network data in the } \\
\text { prediction. }\end{array}$ & $\begin{array}{l}\text { This model requires } \\
\text { training for each } \\
\text { period. }\end{array}$ \\
\hline
\end{tabular}




\begin{tabular}{|c|c|c|c|}
\hline & $\begin{array}{l}\text { The model is evaluated in the telecom field data } \\
\text { to analyze the performance and to compared } \\
\text { with existing models. } \\
\text { The SyriaTel } 9 \text { months data is used to train and } \\
\text { test the developed model. }\end{array}$ & $\begin{array}{l}\text { The performance of the } \\
\text { XGBOOST model has a } \\
\text { higher performance } \\
\text { compared to existing } \\
\text { methods. }\end{array}$ & $\begin{array}{l}\text { The random forest has } \\
\text { the overfitting problem } \\
\text { when the number of } \\
\text { features is high. }\end{array}$ \\
\hline $\begin{array}{l}\text { Amin, } \\
\text { et al. }[2] \\
(2017)\end{array}$ & $\begin{array}{l}\text { Rough set theory is applied to develop the rule- } \\
\text { based decision system for the prediction of } \\
\text { customer churns. } \\
\text { Four rule-based generation methods such as the } \\
\text { LEM2 algorithm (LA), Covering Algorithm } \\
\text { (CA), Genetic Algorithm (GA), and Exhaustive } \\
\text { Algorithm (EA) were used to predict the data. } \\
\text { The developed model is tested on the publicly } \\
\text { available dataset to analyze the efficiency. }\end{array}$ & $\begin{array}{l}\text { The rough set-based } \\
\text { model has a higher } \\
\text { efficiency in classifying } \\
\text { the churns from non- } \\
\text { churns. } \\
\text { The rough set-based GA } \\
\text { method has a higher } \\
\text { performance when } \\
\text { compared to an existing } \\
\text { method. }\end{array}$ & $\begin{array}{l}\text { The rough set-based } \\
\text { model has a lower } \\
\text { efficiency in the } \\
\text { imbalance dataset. } \\
\text { The GA method has } \\
\text { poor convergence in } \\
\text { the analysis. }\end{array}$ \\
\hline $\begin{array}{l}\text { Amin, } \\
\text { et al. }[3] \\
(2019)\end{array}$ & $\begin{array}{l}\text { The data transformation methods like box-cox, } \\
\text { rank and z-score to cross-company churn } \\
\text { prediction (CCCP). } \\
\text { The model is tested with the classifiers such as } \\
\text { Deep Learner Neural Net (DP), Single Rule } \\
\text { Induction (SRI), Gradient Boosted Tree (GBT), } \\
\text { K-Nearest Neighbor (KNN), and Naïve Bayes } \\
\text { model. } \\
\text { The publicly available telecommunication } \\
\text { dataset was used to evaluate the performance of } \\
\text { the developed model. }\end{array}$ & $\begin{array}{l}\text { This result shows that data } \\
\text { transformation such as } \\
\text { box-cox, rank, and log } \\
\text { shows the higher } \\
\text { performance in the CCCP. } \\
\text { The model with Naïve } \\
\text { Bayes has higher } \\
\text { performance compared to } \\
\text { other classifiers. }\end{array}$ & $\begin{array}{l}\text { The data } \\
\text { transformation method } \\
\text { creates the overfitting } \\
\text { problem in the } \\
\text { classifier model. } \\
\text { The naïve Bayes } \\
\text { method processes the } \\
\text { feature independently } \\
\text { with lower efficiency } \\
\text { by analyzing the } \\
\text { feature relationship. }\end{array}$ \\
\hline $\begin{array}{l}\text { Lalwani, } \\
\text { et al. }[4] \\
(2021)\end{array}$ & $\begin{array}{l}\text { The gravitational search algorithm is applied for } \\
\text { the feature selection for customer churn } \\
\text { prediction. } \\
\text { Classifiers such as random forest, decision tree, } \\
\text { support vector machine, naïve Bayes, and } \\
\text { logistic regression are used here in this process. }\end{array}$ & $\begin{array}{l}\text { The result shows that } \\
\text { Adaboost and XGboost } \\
\text { classifier which has } \\
\text { higher performance when } \\
\text { compared to an existing } \\
\text { method. }\end{array}$ & $\begin{array}{l}\text { The Adaboost and } \\
\text { XGboost model has the } \\
\text { limitation of overfitting } \\
\text { problem. }\end{array}$ \\
\hline $\begin{array}{l}\text { Mashraie, } \\
\text { et al. }[5] \\
(2020)\end{array}$ & $\begin{array}{l}\text { The push-pull-mooring framework is applied to } \\
\text { analyze the effect of the features on customer } \\
\text { churns. } \\
\text { The classifiers such as random forest, support } \\
\text { vector machine, logistics regression method } \\
\text { were applied to the customer churn prediction. } \\
\text { Telecommunication data were used to evaluate } \\
\text { the performance of the developed method. }\end{array}$ & $\begin{array}{l}\text { This result shows that the } \\
\text { logistics regression } \\
\text { method has higher } \\
\text { performance for } \\
\text { analyzing the } \\
\text { classification. } \\
\text { The feature selection } \\
\text { process increases the } \\
\text { performance of the } \\
\text { developed method. }\end{array}$ & $\begin{array}{l}\text { The developed method } \\
\text { has the overfitting } \\
\text { problem in the } \\
\text { classification process. } \\
\text { The relation between } \\
\text { the features was not } \\
\text { effectively analyzed in } \\
\text { the classifiers. }\end{array}$ \\
\hline $\begin{array}{l}\text { Idris, } \\
\text { et al. }[6] \\
(2017)\end{array}$ & $\begin{array}{l}\text { The Genetic Programming (GP) and Adaboost } \\
\text { method were applied for the prediction of the } \\
\text { customer churns. } \\
\text { Adaboost based learning method analysis the } \\
\text { features that are selected by the GP method. } \\
\text { The Particle Swarm Optimization (PSO) } \\
\text { method is applied to handle the imbalance } \\
\text { dataset of the telecommunication data. }\end{array}$ & $\begin{array}{l}\text { The GP-Adaboost method } \\
\text { has a higher performance } \\
\text { in the customer churns } \\
\text { prediction. } \\
\text { The PSO method is used } \\
\text { for an under-sampling } \\
\text { method to distribute the } \\
\text { data and reduce the data } \\
\text { imbalance problem. }\end{array}$ & $\begin{array}{l}\text { Adaboost method has } \\
\text { the limitation of the } \\
\text { overfitting problem. } \\
\text { The PSO method has a } \\
\text { poor convergence that } \\
\text { affects the efficiency of } \\
\text { the developed model. }\end{array}$ \\
\hline $\begin{array}{l}\text { Vo, } \\
\text { et al. [7] }\end{array}$ & $\begin{array}{l}\text { The customer churn prediction model is applied } \\
\text { to the unstructured call center data }\end{array}$ & $\begin{array}{l}\text { This result shows that the } \\
\text { developed model has a }\end{array}$ & $\begin{array}{l}\text { overfitting } \\
\text { in the }\end{array}$ \\
\hline
\end{tabular}




\begin{tabular}{|c|c|c|c|}
\hline $\begin{array}{l}(2021) \\
\end{array}$ & $\begin{array}{l}\text { Various text mining techniques such as term } \\
\text { importance, phase embedding, and lexicon } \\
\text { features were applied for the prediction. } \\
\text { Various classifiers such as Gaussian Naïve } \\
\text { Bayes, random forest, logistics regressions were } \\
\text { applied for the prediction. }\end{array}$ & $\begin{array}{l}\text { higher performance in the } \\
\text { prediction. } \\
\text { The XGboost model has a } \\
\text { higher performance for } \\
\text { analyzing } \\
\text { classification. }\end{array}$ & $\begin{array}{l}\text { XGboost is required to } \\
\text { be reduced. } \\
\text { The feature analysis } \\
\text { performance is } \\
\text { required to be } \\
\text { improved. }\end{array}$ \\
\hline $\begin{array}{l}\text { Vijaya } \\
\text { and } \\
\text { Sivasanka } \\
r,[8] \\
(2018)\end{array}$ & $\begin{array}{l}\text { The rough set theory model is applied which } \\
\text { effectively selects the features in the } \\
\text { telecommunication data. } \\
\text { Selected features were applied in the ensemble } \\
\text { methods such as Random subspace, boosting, } \\
\text { and bagging for prediction. } \\
\begin{array}{l}\text { Duke university's churn prediction dataset was } \\
\text { used to evaluate the performance of the } \\
\text { developed model. }\end{array}\end{array}$ & $\begin{array}{l}\text { Attribute selection with } \\
\text { the ensemble } \\
\text { classification method has } \\
\text { higher performance in the } \\
\text { analysis. }\end{array}$ & $\begin{array}{l}\text { The feature selection } \\
\text { method has a lower } \\
\text { efficiency. }\end{array}$ \\
\hline $\begin{array}{l}\text { Caigny, } \\
\text { et al. }[9] \\
(2018)\end{array}$ & $\begin{array}{l}\text { Logit Leaf Model (LLM) is developed for the } \\
\text { prediction of customer churn. } \\
\text { The LLM method is developed on the } \\
\text { segmented data rather than the entire dataset for } \\
\text { better prediction performance. } \\
\text { Decision rules are used to segment the data } \\
\text { where the leaves of the trees are constructed. }\end{array}$ & $\begin{array}{l}\text { The developed model has } \\
\text { higher performance } \\
\text { compared to the decision } \\
\text { tree, random forest, and } \\
\text { logistics regression. }\end{array}$ & $\begin{array}{l}\text { The overfitting } \\
\text { problem affects the } \\
\text { performance of the } \\
\text { developed method. }\end{array}$ \\
\hline $\begin{array}{l}\text { Alboukae } \\
\mathrm{y} \text { et al. } \\
{[10]} \\
(2020)\end{array}$ & $\begin{array}{l}\text { The daily churn prediction model is applied } \\
\text { instead of the monthly prediction model. } \\
\text { RFM based model and statistics-based model } \\
\text { are the two models applied for the prediction of } \\
\text { customer churns. } \\
\text { The LSTM and CNN-based models are the deep } \\
\text { learning techniques that are applied in the } \\
\text { feature selection method. }\end{array}$ & $\begin{array}{l}\text { The LSTM based model } \\
\text { significantly outperforms } \\
\text { the CNN-based model to } \\
\text { predict the customer } \\
\text { churns. } \\
\text { The developed model has } \\
\text { higher performance } \\
\text { compared to the existing } \\
\text { method. }\end{array}$ & $\begin{array}{l}\text { The LSTM model has } \\
\text { an overfitting problem } \\
\text { in the prediction } \\
\text { process. }\end{array}$ \\
\hline $\begin{array}{l}\text { Óskarsdót } \\
\text { tir, et al. } \\
{[11]} \\
(2020)\end{array}$ & $\begin{array}{l}\text { A relational learner is developed based on } \\
\text { various strategies for the prediction of the } \\
\text { customer churn prediction. } \\
\text { Eight call-detail record datasets were used to } \\
\text { evaluate the performance of the developed } \\
\text { method. } \\
\text { Social network data has been used in the method } \\
\text { to improve the performance of the prediction. }\end{array}$ & $\begin{array}{l}\text { A relational learner with } \\
\text { network variables has a } \\
\text { higher performance in the } \\
\text { prediction. } \\
\text { Social network data } \\
\text { improves the performance } \\
\text { of the developed method. }\end{array}$ & $\begin{array}{l}\text { Features of the data are } \\
\text { not effectively } \\
\text { analyzed. } \\
\text { The developed method } \\
\text { has a lower efficiency } \\
\text { in the imbalance } \\
\text { dataset. }\end{array}$ \\
\hline $\begin{array}{l}\text { Ahmed, } \\
\text { et al. }[12] \\
(2017)\end{array}$ & $\begin{array}{l}\text { A metaheuristic-based churn prediction method } \\
\text { is applied in large telecom data. } \\
\text { A hybridized form of the firefly method is } \\
\text { applied for the classification. } \\
\text { Simulated Annealing and the classification are } \\
\text { carried out through the Orange dataset which is } \\
\text { applied to evaluate the performance of the } \\
\text { model. }\end{array}$ & $\begin{array}{l}\text { Firefly algorithm has a } \\
\text { higher performance in the } \\
\text { prediction process. } \\
\text { The hybrid firefly } \\
\text { algorithm has higher } \\
\text { accuracy and lower } \\
\text { latency compared to the } \\
\text { existing method. }\end{array}$ & $\begin{array}{l}\text { The developed method } \\
\text { has a lower } \\
\text { performance in the } \\
\text { imbalanced dataset and } \\
\text { data sparsity. }\end{array}$ \\
\hline
\end{tabular}




\begin{tabular}{|c|c|c|c|}
\hline $\begin{array}{l}\text { Ullah } \\
\text { et al. [13] } \\
(2019)\end{array}$ & $\begin{array}{l}\text { Information gain and correlation attribute } \\
\text { ranking filter methods are applied for the } \\
\text { feature selection in customer churn prediction. } \\
\text { Selected features are applied in the Random } \\
\text { Forest to process the prediction classification. } \\
\text { The influence of the churn factors is analyzed } \\
\text { for the prediction process. }\end{array}$ & $\begin{array}{l}\text { The developed model has } \\
\text { a higher performance in } \\
\text { the customer churn } \\
\text { prediction. } \\
\text { The feature selection } \\
\text { method improves the } \\
\text { performance of the } \\
\text { prediction model. }\end{array}$ & $\begin{array}{l}\text { Some of the selected } \\
\text { features in the analysis } \\
\text { are irrelevant. } \\
\text { The random Forest } \\
\text { method has the } \\
\text { overfitting problem } \\
\text { when the number of } \\
\text { trees are less. }\end{array}$ \\
\hline $\begin{array}{l}\text { Faris [14] } \\
(2018)\end{array}$ & $\begin{array}{l}\text { An intelligent hybrid model is based on the PSO } \\
\text { and Feedforward Neural Network for the } \\
\text { prediction of customer churns. } \\
\text { An oversampling method is applied to the } \\
\text { model for handling the imbalanced dataset. } \\
\text { Two datasets were applied to analyze the } \\
\text { performance of the developed model. }\end{array}$ & $\begin{array}{l}\text { The feature weight } \\
\text { method based on PSO } \\
\text { improves the performance } \\
\text { of the developed method. } \\
\text { The developed model can } \\
\text { handle the imbalance } \\
\text { dataset. }\end{array}$ & $\begin{array}{l}\text { The PSO method has } \\
\text { poor convergence that } \\
\text { affects the performance } \\
\text { of the developed } \\
\text { method. } \\
\text { Feedforward Neural } \\
\text { Network has an } \\
\text { overfitting problem. }\end{array}$ \\
\hline $\begin{array}{l}\text { Vijaya } \\
\text { et al. }[15] \\
(2017)\end{array}$ & $\begin{array}{l}\text { This method applies the three variants of the } \\
\text { PSO method like PSO with feature selection, } \\
\text { PSO with embedded simulated annealing, and } \\
\text { PSO with a combination of feature selection and } \\
\text { simulated annealing. } \\
\text { The developed model is compared with existing } \\
\text { classifiers such as random forest, support vector } \\
\text { machine, and K-nearest neighbor. }\end{array}$ & $\begin{array}{l}\text { The developed PSO } \\
\text { variant has a higher } \\
\text { performance when } \\
\text { compared to the existing } \\
\text { prediction model. } \\
\text { The scalability of the } \\
\text { method is high in the } \\
\text { analysis. }\end{array}$ & $\begin{array}{l}\text { The PSO method has } \\
\text { poor convergence that } \\
\text { affects the performance } \\
\text { of the model. }\end{array}$ \\
\hline
\end{tabular}

\section{PROBLEM DEFINITION}

Many companies require the customer churns prediction model to predict the risk of churns and take necessary care. Various existing models apply the customer churns prediction based on the machine learning methods. Major limitations of customer churn prediction are discussed in this section.

1. Imbalance dataset is one of the common problems in the existing customer churns prediction models and existing models have lower efficiency in handle the imbalance dataset due to insufficient data for the training process.

2. Existing models such as Random forest, support vector machine has the limitation of overfitting problem which present more data instances. The deep learning models such as LSTM and CNN are easily over-fitted in the training process.

3. The random forest method was highly used in the existing models for the prediction of customer churns due to its capacity to effectively analysis the features. The random forest model has the limitation of inefficient performance when the number of a tree is more.

4. Feature selection methods such as PSO and Firefly algorithms were applied to improve the performance of prediction. The PSO and Firefly algorithms have the limitations of poor convergence and high computational time.
5. Support vector machine is applied in the existing customer churns prediction method and SVM can't handle the large dataset. Naïve Bayes has the limitation of processing the feature which independent and lower efficiency in data relation analysis.

\section{CONCLUSION}

Customer churn is one of the major problems in many organizations and customer churn prediction is applied to predict the risk of customer churn to take necessary care. Machine learning techniques were highly applied to predict customer churns. In this paper, various machine learning methods are applied in customer churn prediction which is reviewed with advantages and their limitations. Feature selection methods such as PSO and Firefly algorithm were applied in existing models to improve the efficiency of the prediction model. Random Forest is one of the commonly applied classifiers in customer churn prediction due to its effective analysis of the features in the dataset. Ensemble classifiers such as boosting and bagging were applied in a random forest which achieves higher performance than a single classifier. The deep learning models like LSTM and CNN which has higher efficiency in the prediction model. Random forest, LSTM, and CNN models have the limitations of overfitting in the training process. Feature selection methods such as PSO and Firefly methods have the limitations of poor convergence. Most of the existing 
models have lower efficiency in the imbalance dataset due to limited data instances to train the classifier.

\section{REFERENCES}

[1] A.K. Ahmad, A. Jafar, K. Aljoumaa, Customer churn prediction in telecom using machine learning in the big data platform. Journal of Big Data, vol. 6(1), 2019, pp. 1-24.

[2] Amin, A., Anwar, S., Adnan, A., Nawaz, M., Alawfi, K., Hussain, A. and Huang, K., 2017. Customer churn prediction in the telecommunication sector using a rough set approach. Neurocomputing, 237, pp. 242-254.

[3] Amin, A., Shah, B., Khattak, A.M., Moreira, F.J.L., Ali, G., Rocha, Á. and Anwar, S., 2019. Cross-company customer churn prediction in telecommunication: A comparison of data transformation methods. International Journal of Information Management, 46, pp. 304-319.

[4] Lalwani, P., Mishra, M.K., Chadha, J.S. and Sethi, P., 2021. Customer churn prediction system: a machine learning approach. Computing, pp. 1-24.

[5] Al-Mashraie, M., Chung, S.H. and Jeon, H.W., 2020. Customer switching behavior analysis in the telecommunication industry via push-pullmooring framework: A machine learning approach. Computers \& Industrial Engineering, 144, pp. 106476.

[6] Idris, A., Iftikhar, A. and ur Rehman, Z., 2019. Intelligent churn prediction for telecom using GPAdaBoost learning and PSO undersampling. Cluster Computing, 22(3), pp. 7241-7255.

[7] Vo, N.N., Liu, S., Li, X. and Xu, G., 2021. Leveraging unstructured call $\log$ data for customer churn prediction. Knowledge-Based Systems, 212, pp. 106586.

[8] Vijaya, J. and Sivasankar, E., 2018. Computing efficient features using rough set theory combined with ensemble classification techniques to improve the customer churn prediction in telecommunication sector. Computing, 100(8), pp. 839-860.

[9] De Caigny, A., Coussement, K. and De Bock, K.W., 2018. A new hybrid classification algorithm for customer churn prediction based on logistic regression and decision trees. European Journal of Operational Research, 269(2), pp. 760772 .

[10] Alboukaey, N., Joukhadar, A. and Ghneim, N., 2020. Dynamic behavior based churn prediction in mobile telecom. Expert Systems with Applications, 162, pp. 113779.

[11] Óskarsdóttir, M., Bravo, C., Verbeke, W., Sarraute, C., Baesens, B. and Vanthienen, J.,
2017. Social network analytics for churn prediction in telco: Model building, evaluation and network architecture. Expert Systems with Applications, 85, pp. 204-220.

[12] Ahmed, A.A. and Maheswari, D., 2017. Churn prediction on huge telecom data using hybrid firefly based classification. Egyptian Informatics Journal, 18(3), pp. 215-220.

[13] Ullah, I., Raza, B., Malik, A.K., Imran, M., Islam, S.U. and Kim, S.W., 2019. A churn prediction model using random forest: analysis of machine learning techniques for churn prediction and factor identification in telecom sector. IEEE Access, 7, pp. 60134-60149.

[14] Faris, H., 2018. A hybrid swarm intelligent neural network model for customer churn prediction and identifying the influencing factors. Information, 9(11), pp. 288.

[15] Vijaya, J. and Sivasankar, E., 2019. An efficient system for customer churn prediction through particle swarm optimization based feature selection model with simulated annealing. Cluster Computing, 22(5), pp. 10757-10768.

[16] Z. Guo, Y. Shen, A. K. Bashir, M. Imran, N. Kumar, D. Zhang and K. Yu, "Robust Spammer Detection Using Collaborative Neural Network in Internet of Thing Applications", IEEE Internet of Things Journal, vol. 8, no. 12, pp. 9549-9558, 15 June15, 2021, doi: 10.1109/JIOT.2020.3003802.

[17] L. Tan, H. Xiao, K. Yu, M. Aloqaily, Y. Jararweh, "A Blockchain-empowered Crowdsourcing System for 5G-enabled Smart Cities", Computer Standards

Interfaces, https://doi.org/10.1016/j.csi.2021.103 517

[18] C. Feng et al., "Efficient and Secure Data Sharing for 5G Flying Drones: A Blockchain-Enabled Approach," IEEE Network, vol. 35, no. 1, pp. 130-137, January/February 2021, doi: 10.1109/MNET.011.2000223.

[19] N. Shi, L. Tan, W. Li, X. Qi, K. Yu, “A Blockchain-Empowered AAA Scheme in the Large-Scale HetNet", Digital Communications and

Networks, https://doi.org/10.1016/j.dcan.2020.10 .002 .

[20] Y. Sun, J. Liu, K. Yu, M. Alazab, K. Lin, "PMRSS: Privacy-preserving Medical Record Searching Scheme for Intelligent Diagnosis in IoT Healthcare", IEEE Transactions on Industrial Informatics, doi: 10.1109/TII.2021.3070544.

[21] Z. Guo, L. Tang, T. Guo, K. Yu, M. Alazab, A. Shalaginov, "Deep Graph Neural Network-based Spammer Detection Under the Perspective of Heterogeneous Cyberspace", Future Generation 
Computer

Systems, https://doi.org/10.1016/j.future.2020.11.028.

[22] Bhuvaneswary, N., S. Prabu, S. Karthikeyan, R. Kathirvel, and T. Saraswathi. "Low Power Reversible Parallel and Serial Binary Adder/Subtractor." Further Advances in Internet of Things in Biomedical and Cyber Physical Systems (2021): 151.

[23] Prabu, S., Balamurugan Velan, F. V. Jayasudha, P. Visu, and K. Janarthanan. "Mobile technologies for contact tracing and prevention of COVID-19 positive cases: a cross-sectional study." International Journal of Pervasive Computing and Communications (2020).

[24] Nguyen, Tu N., Bing-Hong Liu, Nam P. Nguyen, and Jung-Te Chou. "Cyber security of smart grid: attacks and defenses." In ICC 2020-2020 IEEE International Conference on Communications (ICC), pp. 1-6. IEEE, 2020.

[25] Pham, Dung V., Giang L. Nguyen, Tu N. Nguyen, Canh V. Pham, and Anh V. Nguyen. "Multi-topic misinformation blocking with budget constraint on online social networks." IEEE Access 8 (2020): 78879-78889.

[26] Naeem, Muhammad Ali, Tu N. Nguyen, Rashid Ali, Korhan Cengiz, Yahui Meng, and Tahir Khurshaid. "Hybrid Cache Management in IoTbased Named Data Networking." IEEE Internet of Things Journal (2021).

[27] Puttamadappa, C., and B. D. Parameshachari. "Demand side management of small scale loads in a smart grid using glow-worm swarm optimization technique." Microprocessors and Microsystems 71 (2019): 102886.

[28] Parameshachari, B. D., H. T. Panduranga, and Silvia liberata Ullo. "Analysis and computation of encryption technique to enhance security of medical images." In IOP Conference Series: Materials Science and Engineering, vol. 925, no. 1, p. 012028. IOP Publishing, 2020.

[29] Rajendran, Ganesh B., Uma M. Kumarasamy, Chiara Zarro, Parameshachari B. Divakarachari, and Silvia L. Ullo. "Land-use and land-cover classification using a human group-based particle swarm optimization algorithm with an LSTM Classifier on hybrid pre-processing remotesensing images." Remote Sensing 12, no. 24 (2020): 4135. 